\title{
Trabalho colaborativo mediado pela aprendizagem ubíqua: Formação continuada entre as professoras que atuam no primeiro ano dos anos iniciais
}

\author{
Trabajo colaborativo mediado por el aprendizaje ubicuo: Formación \\ continuada entre las profesoras que actúan en el primer año de los años \\ iniciales
}
Collaborative work mediated by ubiquitous learning: Continuing education among first-year teachers in initial years

Gislei dos Santos Cruz ${ }^{1}$

Juliana Brandão Machado²

\begin{abstract}
Resumo
O presente artigo analisa o conceito de trabalho colaborativo como formação continuada entre os professores, considerando a mediação da aprendizagem ubíqua. O objetivo é verificar a relevância e as possibilidades do trabalho colaborativo entre as professoras que atuam em uma turma de primeiro ano dos anos iniciais em uma escola pública municipal. As perguntas centrais que orientam este trabalho são: Quais as contribuições do trabalho colaborativo entre os professores? De que maneira as experiências compartilhadas, mediadas pela aprendizagem ubíqua, contribuem na formação continuada de ambos os profissionais? Como são organizadas as ações da prática pedagógica para a turma? O PPP trata a prática do professor na escola como formação continuada dos profissionais envolvidos na sala de aula? A investigação caracteriza-se como uma abordagem qualitativa através da entrevista semiestruturada e a observação direta das ações dos professores na sala de aula. Os conceitos centrais que fundamentam este trabalho são trabalho colaborativo, formação continuada, cibercultura e aprendizagem ubíqua. A análise relata as experiências e as práticas dos professores na sala de aula, com os sucessos alcançados e as dificuldades encontradas que serviram de base para a reconfiguração, reestruturação e organização da atividade pedagógica na sala de aula. $\mathrm{O}$ artigo pretende trazer uma contribuição para a discussão sobre as possibilidades do trabalho colaborativo mediado pela aprendizagem ubíqua.
\end{abstract}

Palavras-chave: Cibercultura; Colaboração; Formação Continuada; Ubíqua

\section{Resumen}

El presente artículo analiza el concepto de trabajo colaborativo como formación continuada entre los profesores, considerando la mediación del aprendizaje ubicuo. El objetivo es a verificar la pertinencia yposibilidades de trabajo colaborativo entre los maestros que trabajan en una clase de primer año de los primeros años en una escuela pública. Las preguntas centrales que orientan este trabajo son: ¿Cuáles son las contribuciones del trabajo colaborativo entre los profesores? Cómo compartido experiencias, mediada por el aprendizaje ubicuo, contribuir a la formación continuada de los profesionales? ¿Cómo se organizan las acciones de la práctica pedagógica para la clase? El PPP trata la práctica del profesor en la escuela como formación continuada de lós profesionales involucrados em el aula? La investigación se caracteriza como un enfoque cualitativo a través de la entrevista semiestructurada y la observación directa de las acciones de los profesores en el aula. Los conceptos

\footnotetext{
1 Mestranda do Programa de Pós-graduação em Educação da Unipampa Campus Jaguarão, RS; Brasil; gisleicruz@hotmail.com

${ }^{2}$ Mestre e doutora em Educação pelo Programa de Pós-graduação em Educação da Universidade Federal do Rio Grande do Sul. Professora Adjunta na Universidade Federal do Pampa, campus Jaguarão; RS; Brasil; julianamachado@unipampa.edu.br
} 
básicos que subyacen a este trabajo son el trabajo colaborativo, la educación continua, la cibercultura y el aprendizaje ubicuo. El análisis relata las experiencias y las prácticas de los profesores en el aula, con los éxitos alcanzados y las dificultades encontradas que sirvieron de base para la reconfiguración, reestructuración y organización de la actividad pedagógica en el aula. El artículo pretende traer una contribución a la discusión sobre las posibilidades del trabajo colaborativo mediado por el aprendizaje ubicuo.

Palabras clave: Cibercultura; Colaboración; Formación Continuada; Ubicuo

\begin{abstract}
This article analyses the concept of collaborative work as continuing education among teachers, considering the ubiquitous learning mediation. The objective is to verify the relevance and the possibilities of the collaborative work between the teachers who work in a first-year class of the initial years in a municipal public school. The central questions that guiding this work are: What are the contributions of collaborative work among teachers? How shared experiences, mediated by ubiquitous learning, contribute to the continuing education of both professionals? How are the actions of the pedagogical practice organized for the class? Does the PPP treat the practice of the teacher in the school as a continuous formation of involved professionals in the classroom? The research is characterized as a qualitative approach through semi-structured interview and direct observation of teachers' actions in the classroom? The central concepts that underlying this work are collaborative work, continuing education, cyberculture and ubiquitous learning. The analysis reports the experiences and teachers 'practices in the classroom, with the successes achieved and the difficulties encountered which served as the basis for the reconfiguration, restructuring and organization of the pedagogical activity in the classroom. The article intends to bring a contribution to the discussion about the possibilities of collaborative work mediated by ubiquitous learning.
\end{abstract}

Keywords: Cyberculture; Collaboration, Continuing Education; Ubiquitous

\title{
1. Introdução
}

A velocidade de transformação da comunicação e da interação, através dos dispositivos móveis, tem cada vez mais auxiliado e facilitado o dia a dia e afazeres das pessoas, assim como a colaboração e a aprendizagem entre elas. Podendo então a "mobilidade ubíqua”, apresentada por Santaella (2013), ser percebida como um viés da ação colaborativa, uma nova maneira de estar, de atuar e agir no mundo a qualquer momento e distância dando forma à cultura contemporânea, a cibercultura. A escola, um local que contempla grande diversidade de saberes e perfis, assim como embasa e objetiva as suas atividades na construção do conhecimento significativo e na formação do ser humano, necessita estar engajada e imersa nessa cultura de interlocução e de colaboração midiática favorecendo, valorizando e compreendendo a formação continuada dos professores por meio do trabalho colaborativo. A pesquisa, a qual trata este artigo, busca mostrar como ocorrem as possíveis ações de colaboração entre os docentes em suas práticas pedagógicas e de que forma se beneficiam da mobilidade a ponto de contribuir e enriquecer a própria formação continuada. Assim, defende-se a ideia de Santos (2014, p. 29), de que "a cibercultura potencializa práticas pedagógicas baseadas em fundamentos valorizados como autonomia, diversidade, dialógica e 
democracia”. O Projeto Político-Pedagógico (PPP) da escola acima referida reconhece a prática educativa do professor na sala de aula como experiência de docência e não na visão de formação continuada, considerada apenas como cursos de curta duração, seminários, palestras, eventos, tampouco trata do registro da produção de conhecimentos por meio do trabalho colaborativo entre os docentes.

A ressignificação das práticas pedagógicas das escolas é um assunto discutido entre as escritas e leituras relacionadas à formação continuada, as discussões e os diálogos entre os próprios professores, comunidade escolar e entre outros tantos pensadores e profissionais. Dessa maneira, mesmo o PPP não enunciando a formação continuada, a escola acolhe e aceita as atividades que propõem qualificação e a interação entre os professores assim como a melhoria do espaço escolar. Baseada nessa questão, como professora do $1^{\circ}$ ano do Ensino Fundamental, percebo a necessidade de fundamentar e organizar os conhecimentos trabalhados com os alunos, contextualizando com a disciplina de espanhol, já que a organização do ano letivo para os anos iniciais na escola disponibiliza aula de 45 minutos deste componente curricular uma vez por semana, ministrada por uma professora com habilitação específica.

O trabalho foi baseado primeiramente nos dados coletados na entrevista com os professores e após nas observações realizadas na sala de aula. Logo, a discussão que segue contemplará a metodologia da pesquisa, o conceito de trabalho colaborativo e aprendizagem ubíqua, com os referenciais teóricos centrais do estudo, a análise dos dados e as considerações finais.

\section{Metodologia da Pesquisa}

A pesquisa foi desenvolvida considerando a atuação de dois professores, professora regular da sala de aula e professora de língua espanhola, em uma turma de $1^{\circ}$ ano do Ensino Fundamental de uma escola pública municipal na cidade de Santa Vitória do Palmar. Primeiramente a pesquisa iniciou com a apresentação e a intenção do tema a ser investigado assim como a solicitação de consentimento dos entrevistados. Objetivou-se a escolha pelo procedimento da entrevista por possibilitar a interação social entre os sujeitos e as possíveis dúvidas surgidas serem sanadas em tempo real. A entrevista, segundo Ludke e André, "permite correções, esclarecimentos e adaptações que a torna sobremaneira eficaz na obtenção das informações desejadas”. (1994, p. 34). Assim, a escola disponibilizou um 
espaço onde pudesse ocorrer a entrevista entre entrevistadas e pesquisadora, viabilizando o diálogo tranquilo e com precisão de respostas. Os questionamentos trataram diretamente da prática e da formação dos docentes: O que compreende por trabalho colaborativo entre os docentes na prática escolar? As ações pedagógicas para o $1^{\circ}$ ano contemplam um planejamento organizado juntamente com outra professora da turma? De que maneira o trabalho colaborativo pode vir a contribuir com a formação continuada do professor? Diante do avanço tecnológico, da cultura contemporânea em que vivemos, a cibercultura, de que forma você utiliza os dispositivos digitais móveis em sua prática pedagógica para a busca de informações, conhecimentos, recursos, pesquisas e interação com os demais professores que atuam na turma do $1^{\circ}$ ano?; De que maneira a ubiquidade, capacidade de um indivíduo poder estar presente em vários lugares ao mesmo tempo no contexto da cibercultura, pode ser uma possibilidade de contribuir e compartilhar experiências entre os docentes?

Na sequência, foi realizada a organização das observações das práticas pedagógicas que atentam ao trabalho colaborativo entre os docentes e a utilização dos dispositivos digitais móveis dentro e fora do espaço escolar. Ficou acertado que as observações ocorreriam duas vezes por semana, durante um mês, configurando um total de quatro observações na aula de cada professora. Segundo Ludke e André (1986, p. 25), "a observação é um dos instrumentos básicos para a coleta de dados na investigação qualitativa”.

Na segunda fase da pesquisa, após ter organizado os dados iniciais da entrevista, deuse início às observações, que muito contribuíram para expressar as dificuldades e possibilidades que os docentes enfrentam e buscam no dia a dia na sala de aula. Os dados obtidos nas ações seguem na sequência acompanhada pelos conceitos da discussão.

\section{Trabalho colaborativo como formação continuada}

Pensar no professor na atualidade significa um profissional mediador do ensino e aprendizagem que se constitui na ação e com o outro, na intenção de somar experiências válidas e significativas para a aprendizagem individual e do coletivo.

Compreende-se trabalho colaborativo como um processo de trabalho articulado e pensado em conjunto, que permite alcançar melhor os resultados visados, com base no enriquecimento trazido pela interação e dinâmica de vários saberes específicos e de vários processos cognitivos (ROLDÃO, 2007, p. 27).

Segundo Nóvoa (1997, p. 26) “A troca de experiências e a partilha de saberes consolidam espaços de formação mútua, nos quais cada professor é chamado a desempenhar, simultaneamente, o papel de formador e de formado". Assim, permite à escola ser um 
ambiente de partilhas e de construção de conhecimentos que enriquecem e possibilitam melhor reflexão e reorganização das práticas pedagógicas.

A partilha de experiências, por meio da aprendizagem colaborativa, torna-se uma relação de reciprocidade entre os sujeitos, resultando na aprendizagem significativa. Assim, Damiani (2010, p.225) relata que "o trabalho colaborativo possibilita o resgate de valores como o compartilhamento e a solidariedade que se foram perdendo ao longo do caminho trilhado por nossa sociedade competitiva e individualista". A ação colaborativa entre os profissionais por si é uma aprendizagem coletiva que fortalece os sujeitos num intercâmbio de ideias e permite que se compreendam as relações interpessoais. $\mathrm{O}$ aprender coletivo pode causar mudanças positivas quanto ao desenvolvimento cognitivo e social dos docentes à medida que possibilita a afirmação da autonomia, da participação, da colaboração, da discussão de ideias a partir de opiniões diversas, formando um caminho de mão dupla e um percurso de formação continuada para assim qualificar também o espaço escolar.

Porém, tal formação algumas vezes é percebida, entre os professores, apenas como formatos de cursos de curta duração, capacitações, especializações, eventos, entre outros. Desconsideram a experiência docente constituída pela prática pedagógica, pela interação e a mediação da atividade escolar. Assim, defendemos a ideia de que a construção do saber docente não deve ser somente um agregado de informações e conhecimentos teóricos, mas vivências e experiências compartilhadas, a prática da reflexão sobre as mesmas e a ressignificação das intenções pedagógicas que se constituem no trabalho colaborativo. Tardif (2014, p. 39) explicita:

Os docentes, no exercício de suas funções e na prática de sua profissão, desenvolvem saberes específicos, baseados em seu trabalho cotidiano e no conhecimento de seu meio [...] os quais brotam da experiência e são por ela validados.

Assim, o autor nos revela a importância e o significado da prática e da experiência a qual se validam pelas ações e conhecimentos específicos que os professores constroem no meio e com quem atuam. São saberes importantes para a formação docente e que consolidam o processo de ensino e aprendizagem enquanto profissionais da educação.

Logo, o desenvolvimento contínuo faz parte do processo de formação continuada e os avanços da contemporaneidade vão tomando espaço e fazendo parte do constituir-se professor. Dessa forma, acompanhar a evolução do mundo contemporâneo é algo que exige dos profissionais da educação a incessante busca pela informação, atualização e transformação, que acompanhada de alguns recursos inovadores poderão resultar em uma melhor reflexão sobre a sua prática e reestruturação do fazer pedagógico. "Toda relação com 
o saber (com o aprender) é também relação com o mundo, com os outros e consigo. Não existe saber (de aprender) se não está em jogo a relação com o mundo, com os outros e consigo" (CHARLOT, 2005, p. 58). Constituir-se professor é incessante perante as tantas transformações e diversidades na escola, a diversificadas maneiras de leitura, escrita e interações. A prática da interação mediada pelos dispositivos móveis possibilita que os sujeitos geograficamente dispersos atuem em conjunto, mesmo que através da comunicação assíncrona, proporcionando uma conexão contínua. "Essa conectividade intensifica a colaboração em tempo real ou interatividade instantânea, que pode permitir melhores tomadas de decisões" (SANTAELLA, 2013, p. 292). Atualmente podemos utilizar diferentes linguagens através das mídias, o que Santaella (2002) chama de "ecologia das mídias", ou seja, uma sociedade que evolui pela mediação e midiatização ente os sujeitos e os espaços. E assim, os professores, por meio dos aplicativos digitais, poderão utilizar-se das competências da contemporaneidade, cibercultura e ubiquidade, para contextualizar os conhecimentos trabalhados na sala de aula, trocar informações necessárias ou urgentes quanto à reestruturação de uma atividade anteriormente planejada.

Organizar e reorganizar as atividades diárias, contextualizar atividades significativas, refletir sobre as ações pedagógicas e dar significado às aprendizagens dos alunos utilizando-se de recursos como áudios, vídeos, fotos, QR Code e links que servirão para enriquecer ou produzir conhecimentos tanto para as professoras como para os alunos. A mobilidade e a intensidade da internet pluralizam as informações que o indivíduo recebe dando amplo espaço para a diversificação do conhecimento. "A fertilização de ideias é aperfeiçoada pelo amplo acesso a redes globais" (SANTAELLA, 2013, p. 15). Percebe-se uma nova condição do leitor, aquele que mergulha na busca, que interpreta signos, que compreende diversas linguagens e imagens imersas no mundo contemporâneo independente de tempo e espaço, geograficamente distante, mas ao mesmo tempo presente e atuante na rede. Podemos utilizar as diferentes linguagens através das mídias, o que Santaella (2002) chama de "ecologia das mídias", ou seja, uma sociedade que evolui pela mediação e midiatização entre os sujeitos e os espaços. E assim, os professores, por meio dos aplicativos digitais, poderão beneficiar-se das competências da contemporaneidade para contextualizar os conhecimentos trabalhados na sala de aula, trocar informações necessárias ou urgentes quanto à reestruturação de uma atividade anteriormente planejada, participar de comunidades culturais, ampliar a interação social, enfim, beneficiar-se dos infinitos recursos disponíveis na nova cultura emergente.

\section{As contribuições da aprendizagem ubíqua em práticas pedagógicas docentes}


Pensando em formação docente, é possível perceber quantos ainda muitos profissionais da educação resistem, têm dificuldades, não compreendem ou desconhecem as diversas possibilidades que os dispositivos digitais móveis oportunizam e podem contribuir em suas práticas pedagógicas. Esta pode ser uma forma de atuarem colaborativamente com os demais professores do ambiente escolar, proporcionando a formação continuada entre os sujeitos. Faz-se necessário acompanhar, na esfera educacional, a geração nativa digital, mobilizando saberes, proporcionando e favorecendo a aprendizagem contínua e construtiva.

“A fertilização de ideias é aperfeiçoada pelo amplo acesso a redes globais. Com a internet aliada à mobilidade, aumenta a quantidade de informação e o conhecimento não apenas cresce, mas também se diversifica”. (SANTAELLA, 2013, p. 14)

Atualmente, temos em mãos as informações que desejamos, que necessitamos, que nos causam curiosidades, dúvidas, satisfação e que contribuem para o nosso conhecimento. E assim, vai ganhando uma nova forma o modo como nos deslocamos, percorremos entre idas e vindas uma rede de dados mesmo estando estáticos ou cumprindo outros afazeres e obrigações. O conhecimento à mão de todos a qualquer hora e lugar possibilitado pela ubiquidade, possibilitando o sujeito de atuar e interagir em vários locais virtuais ou físicos, com diversos grupos ou individualmente a respeito de um determinado assunto ou informação por meio de dispositivos digitais móveis. "A tecnologia da mobilidade ubíqua caracteriza-se pela conexão constante e ubíqua com o ciberespeço, com espaços urbanos e interações sociais diversas com e nesses espaços” (Santaella, 2007, p. 236). Tal interação móvel, independente de tempo e espaço, permitida pela ubiquidade, é pertinente e auxilia as professoras não somente quanto à organização dos planejamentos, mas também quanto ao uso dos recursos do mundo digital multifacetado pela velocidade, acessibilidade e mobilidade comunicacional: "Quando a informação é ubíqua, ela auxilia e fortalece a aquisição de conhecimentos, de certo modo, naturalizando a sua absorção" (SANTAELLA, 2013, p. 293).

Porém, as entidades escolares são estruturadas e organizadas por documentos e regimentos que norteiam a proposta escolar e tais acervos algumas vezes não contemplam os meios e fins que percorrem a dinâmica que acontece na sala de aula, tampouco os recursos tecnológicos digitais necessários. No contexto da pesquisa, a organização das ações da prática de atividades para a turma era planejada de maneira individual, contextualizada, mas cada professora dentro de sua própria ação, não havendo conexão entre os conhecimentos trabalhados e os períodos de aula. Diante das observações e diálogos com outros docentes, 
percebo que fatos como esse são comuns de ocorrerem nas salas de aula, assim como também demonstraram interesse nessa maneira de reestruturar a atuação pedagógica.

Para que os professores ressignifiquem a sua prática é preciso que a teorizem. E este movimento de teorizar a prática não se efetiva somente com treinamentos, palestras, seminários, aulas expositivas, mas muito mais, quando há uma relação dinâmica com a prática deste professor a partir de uma reflexão coletiva, auto reflexão, pensamento crítico e criativo, via educação continuada. É preciso desencadear estratégias de formação processuais, coletivas, dinâmicas e contínuas. Refletir com os demais professores e compartilhar erros e acertos, negociar significados e confrontar pontos de vista surge como algo estimulador para uma prática pedagógica comprometida. (RAUSCH e SCHLINDWEIN, 2001, p. 121)

É comum o trabalho individual nas ações pedagógicas dos professores e pelo que se percebe há muito que buscar para a desconstrução dessa prática ou reorganizá-la. Fullan e Hargreaves (2000) defendem a reconciliação dos dois tipos de atividades - grupais e individuais - entendendo que qualquer delas, sem a outra, limita o potencial de trabalho dos professores. No entanto, o cenário educacional da turma do $1^{\circ}$ ano aqui analisada, em nenhum momento, durante as observações, transpareceu à visão da pesquisadora a contextualização e o planejamento colaborativo das atividades entre os docentes. Ocorreram dinâmicas e eventos que seguiam um mesmo calendário, plano curricular e projetos, mas sem conexão e articulação anteriormente pensada e objetivada. Quanto às entrevistas, as professoras transpareceram claramente a necessidade da utilização dos recursos e ferramentas disponíveis no mundo contemporâneo como a seguir: É preciso atualizar-se; A tecnologia está no nosso dia a dia; É preciso acompanhar a nova geração; Não há mais como atuar sem a interação com a internet; Busco algumas atividades para os alunos em sites educacionais; Combinamos os detalhes e resolvemos imprevistos de algumas festividades e ações na escola através do grupo de Whatsapp. Ao mesmo tempo em que declararam as dificuldades, as quais encontram no momento de organizar a metodologia de maneira que permita a participação, a efetivação da aprendizagem e o conhecimento significativo mediado e instrumentalizado pelos dispositivos móveis digitais emergem nas falas das professoras: "A escola não oferece rede Wi-fi"; "Tenho dificuldades em organizar atividades para os alunos com a tecnologia”; "Atuo em colaboração com as demais colegas através de recados, avisos e algumas ideias através do celular". A atuação das profissionais em relação à internet ficou reduzida à participação e interação em redes sociais, recados, informações, imagens e fotos em grupos fechados inclusive da escola, busca de conteúdos e atividades a serem trabalhadas em sala de aula. O exercício deste trabalho possibilitou e provocou uma reflexão e percepção diante da prática pedagógica que ali ocorre, transparecendo o quanto é importante, prazeroso e menos exaustivo o trabalho quando compartilhado e pensado coletivamente, inclusive na questão de 
economia de tempo e qualidade na aprendizagem dos alunos. Em uma das declarações uma professora afirmou que não desconhecia o significado de trabalho colaborativo, mas que nunca havia refletido a respeito entre os colegas docentes: "Aprendemos observando as práticas de outras colegas, assim como opinando e auxiliando-as, porém nunca tomamos esses simples atos como parte da formação continuada entre nós”. Quanto mais envolvidos numa ação ou atividade, mais podemos nos beneficiar dos saberes e colaborar com a aprendizagem do outro. Logo, as relações entre o trabalho colaborativo e individual dos docentes, ambas em sintonia e aliadas à mobilidade, favorecem a tomada de decisões e a resolução de problemas baseados em princípios e de modo emancipatório diante de contínuas mudanças sociais dentro e fora do ambiente escolar.

\section{Considerações Finais}

Este trabalho apontou algumas contribuições que o trabalho colaborativo mediado pela aprendizagem ubíqua pode proporcionar à formação continuada dos professores possibilitando a pluralização dos saberes e fazeres por meio da ubiquidade entre os docentes através de uma prática pedagógica emancipatória, inclusiva e com maior envolvimento dos sujeitos na busca pela resolução de problemas, situações de conflitos e a conquista de melhorias do ambiente escolar dando significado relevante às propostas feitas aos alunos.

No entanto, na turma de $1^{\circ}$ ano da escola pesquisada, percebeu-se que, apesar de contextualizadas de acordo com o calendário escolar, as atividades planejadas pelas professoras que atuam na sala, não são organizadas por meio da colaboração e utilizam-se das tecnologias como um recurso informal para situações ocasionais, desconhecendo a prática pedagógica como formação continuada e declarando as dificuldades encontradas por elas no uso das tecnologias para o planejamento das práticas pedagógicas. As profissionais compreendem o mundo digital da atualidade, percebem a necessidade e a importância das tecnologias em seus afazeres, utilizam-se das redes sociais para interagir, buscam em ambientes educacionais atividades para os planejamentos mesmo com algumas dificuldades na utilização das TIC em suas práticas e a falta de acesso à internet por rede wi-fi no espaço escolar. O próprio PPP da referida escola não trata a questão da formação permanente a não ser em situações planejadas, organizadas, certificadas ou diplomadas, como no caso de cursos, palestras, especializações e outros. Nesse contexto as ações coletivas apresentam-se fragilizadas, supõem-se algumas condições necessárias para o planejamento compartilhado tais como: a participação, a autonomia, a aceitação da diversidade, o diálogo e a democracia 
permitindo a reflexão da ação docente, a prática da cultura participativa e a relevância do trabalho colaborativo como formação continuada numa ação plural de aprendizagem utilizando-se da mobilidade e da ubiquidade, uma docência conectada ao cenário da comunicação para que assim possa reinventar o espaço escolar na contemporaneidade.

\section{Referências}

DAMIANI, M. F.; PORTO, T. M. E. SCHLEMMER, E. (Org.). Trabalho colaborativo em educação: uma possibilidade para ensinar e aprender. São Leopoldo: Oikos; Brasília: Líber Livro, 2010.

DEMO. Pedro. Metodologia científica em ciências sociais. $3^{\text {a }}$ Ed., São Paulo, Atlas, 1995.

LUCK, Heloisa. Perspectivas da gestão educacional. Concepções e processos democráticos de gestão educacional. Editora Vozes, 2010.

LÜDKE, M.; ANDRÉ, M. Pesquisa em educação: abordagens qualitativas. São Paulo: EPU, 1994

MANZINI, Eduardo José. Entrevista semiestruturada: análise de objetivos e de roteiros. In: Seminário Internacional de Pesquisa e estudos qualitativos, 2. A pesquisa qualitativa em debate. Bauru: SIPEQ, 2004.

MINAYO. Maria Cecília de S. O desafio do conhecimento: pesquisa qualitativa em saúde. 3. ed. São Paulo: Hucitec/Rio de Janeiro: Abrasco, 1996.

NÓVOA, A. Prefácio. In: JOSSO, Marie-Christine. Experiências de vida e formação. São Paulo: Cortez Editora, 2004, p. 11-34.

NÓVOA, Antonio. Formação de professores e profissão docente. Os professores e a profissão. Lisboa: Dom Quixote, 1992

NÓVOA, Antônio. Vidas de Professores. Portugal: Porto, 1999.

OLIVEIRA. Sandra Alves. O trabalho colaborativo e o desenvolvimento profissional de um grupo de professores dos anos iniciais: olhar para resolução de problemas. Cad. Pesq., São Luís, v. 24, n. Especial, set./dez. 2017.

RAUSC, R. B.; SCHLINDWEIN, L. M. As ressignificações do pensar/fazer de um grupo de professoras das séries iniciais. Contrapontos, Itajaí, v. 1, n. 2, p. 109-23, 2001

ROLDÃO. M. (2007). “Colaborar é preciso: Questões de qualidade e eficácia no trabalho dos professores”. Revista Noesis, nº71, 24-29.

SANTAELLA, Lucia. Linguagens líquidas na era da mobilidade. São Paulo: Paulu Paulus, 2009. 
SANTAELlA, Lucia. Comunicação ubíqua: repercurssões na cultura e educação. São Paulo: Paulus, 2013. (Coleção Comunicação)

TARDIF, Maurice. Saberes docentes e formação profissional. 16. Ed. Petrópolis, RJ: Vozes, 2014. 